\title{
First record of the genus Restiosporium (Websdaneaceae, Ustilaginales) outside Australasia: documenting R. spathace $i$ in Thailand
}

\section{Teodor T. Denchev ${ }^{1,2 *} \&$ Cvetomir M. Denchev ${ }^{1,2}$}

${ }^{1}$ Institute of Biodiversity and Ecosystem Research, Bulgarian Academy of Sciences, 2 Gagarin St., 1113 Sofia, Bulgaria

${ }^{2}$ IUCN SSC Rusts and Smuts Specialist Group

Received 6 December 2021 / Accepted 22 December 2021 / Published 27 December 2021

Denchev, T.T. \& Denchev, C.M. 2021. First record of the genus Restiosporium (Websdaneaceae, Ustilaginales) outside Australasia: documenting R. spathacei in Thailand. - Mycobiota 11: 17-21. doi: 10.12664/ mycobiota.2021.11.03

\begin{abstract}
The genus Restiosporium consists of 21 species on hosts in the Restionaceae. It was known only from Australia and New Zealand. Restiosporium is reported here for the first time outside Australasia, based on a specimen of $R$. spathacei on Dapsilanthus disjunctus from Thailand. A description and illustrations are provided for this smut fungus. Dapsilanthus disjunctus is a new host plant for Restiosporium spathacei.

Key words: Australasia, Dapsilanthus disjunctus, Restionaceae, Restiosporium spathacei, smut fungi, taxonomy, Thailand, Websdaneaceae
\end{abstract}

\section{Introduction}

The representatives of the Restionaceae are evergreen, rush-like plants, mostly dioecious or rarely monoecious, with erect photosynthetic culms and leaves reduced to sheaths. The family contains ca. 500 species, distributed almost entirely in the Southern Hemisphere, with the great majority of the species restricted to southwestern Africa and Australia. Four species are known from New Zealand, one from Chile, and only one species is distributed north of the Equator, in Southeast Asia (Linder 1984; Linder et al. 1998; Briggs \& Linder 2009).

Twenty-two smut fungi are described on hosts in the Restionaceae, all from Australia or New Zealand: one species in the monotypic genus Websdanea (Vánky 1997) and 21 species

\footnotetext{
*Corresponding author: e-mail: ttdenchev@gmail.com
} 
in the genus Restiosporium (Vánky 2000, 2003, 2006, 2007; Vánky \& McKenzie 2002; Vánky \& Shivas 2003). It is important to note that despite of the fact that most members of this family are distributed in Africa (ca. 330 species), and intensive field research and herbarium observations are carried out, no smut fungus has yet been found in Africa (Vánky 2006; Vánky et al. 2011).

During an examination of specimens of the Restio family in the herbarium of the National Museum of Natural History, Paris (P), a specimen of Dapsilanthus disjunctus from Thailand, infected by a smut fungus, was found. This fungus was identified as Restiosporium spathacei.

Dapsilanthus B.G. Briggs \& L.A.S. Johnson (Restionaceae) is a small genus in the subfam. Leptocarpoideae. It comprises four species, three in seasonally wet sites in northern Australia and monsoonal areas of southern New Guinea and the Aru Islands, and one species in Southeast Asia (Laos, Thailand, Vietnam, Cambodia, Malaysia, and Hainan Island) (Linder et al. 1998; Wu \& Larsen 2000; Briggs \& Linder 2009).

All species of Restiosporium produce their sori in the fruits (capsules or nuts), replacing the seeds by a black or blackish brown, first agglutinated, later granular-powdery to powdery mass of spore balls. The spore balls are usually rather loose, easily separating into single spores, more rarely they are persistent (Vánky 2006, 2011). Restiosporium spathacei is reported here for the first time from Thailand (cf. Shivas et al. 2007, 2013) and, furthermore, a species of Restiosporium is reported for the first time outside Australasia.

\section{Material and methods}

A dried specimen from the herbarium of the National Museum of Natural History, Paris was examined under light microscope (LM) and scanning electron microscope (SEM). For LM observations and measurements, spore balls were mounted in lactoglycerol solution ( $\mathrm{w}$ $:$ la $: \mathrm{gl}=1: 1: 2$ ) on glass slides, gently heated to boiling point to rehydrate the spores and then cooled. The measurements of spores are given as min-max (extreme values) (mean \pm 1 standard deviation). For SEM, spore balls were attached to specimen holders by doublesided adhesive tape and coated with gold using an ion sputter coater. The surface structure of spores was observed and photographed at $10 \mathrm{kV}$ accelerating voltage using a Hitachi SU3500 scanning electron microscope. The description below is based entirely on the specimen examined. The shapes of spore balls and spores are arranged in descending order of frequency.

\section{Taxonomy}

Restiosporium spathacei Vánky, R.G. Shivas \& C. Vánky, in Vánky, Mycol. Balcan. 3: 41, 2006. - Holotype on Dapsilanthus spathaceus (R. Br.) B.G. Briggs \& L.A.S. Johnson, Australia, Queensland, Cape York Peninsula, $18 \mathrm{~km} \mathrm{SSW}$ of Bamaga, 10 ${ }^{\circ} 58^{\prime} 6.2^{\prime \prime} \mathrm{S}$, $142^{\circ} 20^{\prime} 1.7^{\prime \prime}$ E, alt. ca 30 m, 8 March 2000, leg. R.G. Shivas, C. \& K. Vánky, s.n. (BRIP 26 965; isotype HUV 20 965).

Figs 1-5 


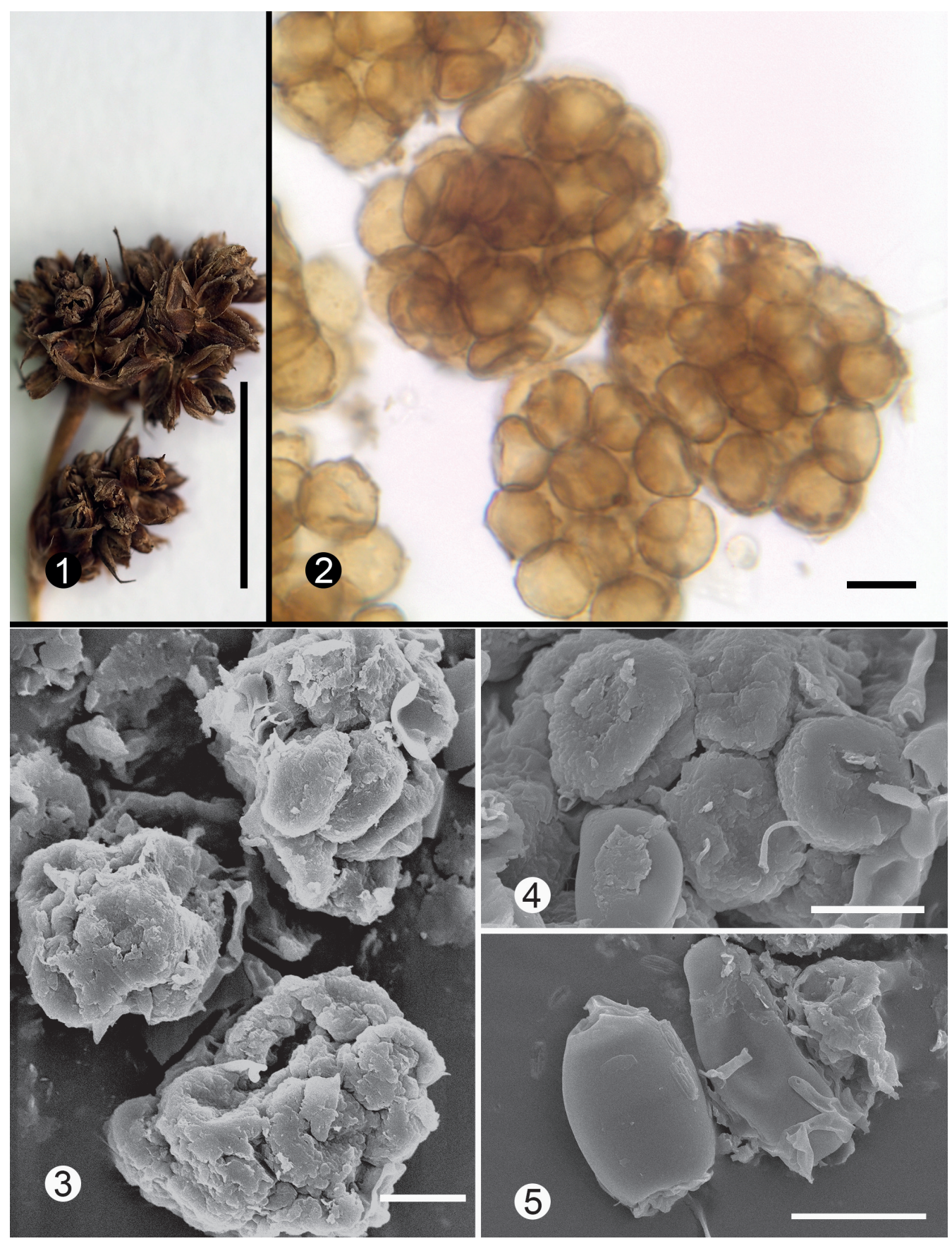

Figs 1-5. Restiosporium spathacei on Dapsilanthus disjunctus (P-P03657860). 1. Habit. 2. Spore balls in LM. 3-5. Spore balls in SEM. Scale bars: $1=0.5 \mathrm{~cm}, 2=10 \mu \mathrm{m}, 3-5=5 \mu \mathrm{m}$ 
Infection systemic. Sori in all nutlets of infected plant, partially visible between the spreading glumes, ellipsoidal or ovoid, ca. $1.0 \times 0.5 \mathrm{~mm}$, filled with a granular-powdery, blackish brown mass of spore balls. Spore balls subglobose, irregular or broadly ellipsoidal, 26-60 × 23-46 $\mu \mathrm{m}$, medium to dark reddish brown, composed of 10-30 easily separating spores. Spores subglobose, broadly ellipsoidal, irregular, ellipsoidal or ovoid, often with 1-2 flattened sides, (10-)10.5-15.5(-16.5) × (8-)9-12(-13.5) (12.4 $\pm 1.2 \times 10.5 \pm 0.8)$ $\mu \mathrm{m}(\mathrm{n}=100)$, light to medium yellowish brown; wall 0.6-0.9 $\mu \mathrm{m}$ thick, smooth. In SEM, spore wall smooth on the contact sides and rugulose to minutely verruculose on the free surface.

Specimen examined - On Dapsilanthus disjunctus (Mast.) B.G. Briggs \& L.A.S. Johnson: THAILAND, RAYONG PROVINCE, $5 \mathrm{~km}$ E of Ban Phe, $12^{\circ} 38^{\prime} \mathrm{N}, 101^{\circ} 26^{\prime} \mathrm{E}$, 1972 , leg. K. Larsen, S.S. Larsen, I. Nielsen \& T. Santisuk, in Flora of Thailand Project, $4^{\text {th }}$ Expedition 1972, no. 32436 (P-P03657860; as 'Leptocarpus disjunctus').

Distribution - On Restionaceae: Dapsilanthus disjunctus (Leptocarpus disjunctus Mast.), D. spathaceus (R. Br.) B.G. Briggs \& L.A.S. Johnson (Leptocarpus spathaceus R. Br.); Asia (Thailand) and Australia (Queensland).

Restiosporium spathacei was known only from the type collection on Dapsilanthus spathaceus, from Queensland. The specimen reported here represents the second record of this smut fungus. Dapsilanthus disjunctus is a new host plant for Restiosporium spathacei.

Two smut fungi are described on hosts in Dapsilanthus: Restiosporium dapsilanthi Vánky on Dapsilanthus elatior (R. Br.) B.G. Briggs \& L.A.S. Johnson (known only from the type collection, from Queensland), and $R$. spathacei. Restiosporium spathacei is distinguished from $R$. dapsilanthi by having thinner spore wall $(0.5-0.9 \mu \mathrm{m}$ thick vs. $1-2(-3) \mu \mathrm{m}$ thick for $R$. dapsilanthi, as seen in LM), and smooth spores on the contact sides (Fig. 5) vs. minutely verruculose-echinulate spores for $R$. dapsilanthi, as seen in SEM (Vánky 2006).

Acknowledgements. This study was supported by the Bulgarian Science Fund (Grant no. KP-06-N51/10/16.11.2021). The visit to the herbarium of the National Museum of Natural History, Paris was carried out in the framework of the SYNTHESYS Project (http://www. synthesys.info/) financed by European Community Research Infrastructure Action under the FP7 “Capacities” Program (Grant no. FR-TAF-5919).

\section{ORCID}

Teodor T. Denchev, https://orcid.org/0000-0002-7242-3307

Cvetomir M. Denchev, https://orcid.org/0000-0001-6301-1629

\section{References}

Briggs, B.G. \& Linder, H.P. 2009. A new subfamilial and tribal classification of Restionaceae (Poales). Telopea 12: 333-345.

https://doi.org/10.7751/telopea20095822 
Linder, H.P. 1984. A phylogenetic classification of the genera of the African Restionaceae. - Bothalia 15:11-76.

Linder, H.P., Briggs, B.G. \& Johnson, L.A.S. 1998. Restionaceae. - In: K. Kubitzki (ed.). The families and genera of vascular plants. Vol. 4. Flowering plants. Monocotyledons: Alismatanae and Commelinanae (except Gramineae), pp. 425-445. Springer, Berlin, Heidelberg.

https://doi.org/10.1007/978-3-662-03531-3_41

Shivas, R.G., Athipunyakom, P., Likhitekaraj, S., Butranu, W., Bhasabutra, T., Somrith, A., Vánky, K. \& Vánky, C. 2007. An annotated checklist of smut fungi (Ustilaginomycetes) from Thailand. - Australasian Plant Pathology 36: 376-382.

https://doi.org/10.1071/AP07036

Shivas, R.G., Athipunyakom, P., Beasley, D.R., McTaggart, A.R. \& Vánky, K. 2013. Smut Fungi of Thailand. Biosecurity Queensland, Department of Agriculture and Fisheries, Brisbane, Australia. Available from: http://collections.daff.qld.gov.au/thaismutfungi/ (accessed on 28 November 2021).

Vánky, K. 1997. Websdanea, a new genus of smut fungi. - Mycotaxon 65: 183-190.

Vánky, K. 2000. New taxa of Ustilaginomycetes. - Mycotaxon 74: 343-356.

Vánky, K. 2003. Taxonomical studies on Ustilaginales. 23. - Mycotaxon 85: 1-65.

Vánky, K. 2006. The smut fungi (Ustilaginomycetes) of Restionaceae s. lat. - Mycologia Balcanica 3: 19-46.

Vánky, K. 2007. Taxonomic studies on Ustilaginomycetes - 27. - Mycotaxon 99: 1-70.

Vánky, K. \& McKenzie, E.H.C. 2002. Two new species of Ustilaginomycetes from New Zealand. - New Zealand Journal of Botany 40: 117-121.

https://doi.org/10.1080/0028825X.2002.9512775

Vánky, K. \& Shivas, R.G. 2003. Further new smut fungi (Ustilaginomycetes) from Australia. - Fungal Diversity 14: 243-264.

Vánky, K., Vánky, C. \& Denchev, C.M. 2011. Smut fungi in Africa - a checklist. - Mycologia Balcanica 8: $1-77$. https://doi.org/10.5281/zenodo.2550336

Vánky, K. 2011['2012']. Smut fungi of the world. APS Press, St. Paul, Minnesota.

Wu, G.F. \& Larsen, K. 2000. Restionaceae. - In: Z.Y. Wu \& P.H. Raven (eds.). Flora of China. Vol. 24, 2. Flagellariaceae through Marantaceae. Science Press, Beijing, and Missouri Botanical Garden Press, St. Louis. 